\title{
Bazı üzüm (Vitis vinifera L.) çeşitlerine ait salkım iskeletlerinin toplam fenolik bileşik ve trans-resveratrol düzeyleri
}

\section{Total phenolic compound and trans-resveratrol levels of some grape (Vitis vinifera L.) stems}

\author{
Hande Tahmaz KARAMAN ${ }^{1 *}$, Damla Yüksel KÜSKÜ² ${ }^{\text {ID }}$, Gökhan SÖYLEMEZOĞLU1 ${ }^{1 D}$ \\ ${ }^{1}$ Ankara Üniversitesi Ziraat Fakültesi Bahçe Bitkileri Bölümü, 06110, Dışkapı, Ankara \\ ${ }^{2}$ Bilecik Şeyh Edebali Üniversitesi Meslek Yüksekokulu Park ve Bahçe Bitkileri Bölümü, 11230, Bilecik
}

\section{To cite this article:}

öz

Karaman, H.T., Küskü, D.Y.\& Söylemezoğlu, G. (2020). Bazı üzüm (Vitis vinifera L.) çeşitlerine ait salkım iskeletlerinin toplam fenolik bileşik ve transresveratrol düzeyleri. Harran Tarım ve Gıda Bilimleri Dergisi, 24(2): 222228.

DOI: 10.29050/harranziraat.651668

Address for Correspondence: Hande Tahmaz KARAMAN e-mail:

tahmazhande@gmail.com

\section{Received Date:}

27.11.2019

Accepted Date:

15.05.2020

(C) Copyright 2018 by Harran University Faculty of Agriculture. Available on-line at www.dergipark.gov.tr/harranziraat

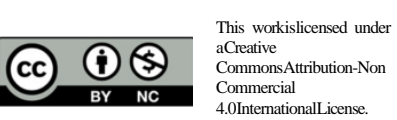

Üzüm çekirdekleri, kabukları ve şarabın insan sağlığına olan etkileri ile ilgili çok yoğun araştırma gerçekleştirilmesine rağmen salkım iskeletleri ile ilgili yok denecek kadar az çalışma bulunmaktadır. Bu araştırmanın temel amacı 49 adet Vitis vinifera L. çeşidine ait salkım iskeletlerinin toplam fenolik bileşik (TFB), trans-resveratrol, kateşin ve epikateşin düzeylerinin belirlenmesidir. TFB düzeyi 17025-123250 mg GAE kg ${ }^{-1}$ kuru ağırlık, trans-resveratrol düzeyi 23.44-70.38, kateşin düzeyi 843-14144 ve epikateşin düzeyi $0-981 \mathrm{mg} \mathrm{kg}^{-1}$ kuru ağırlık aralıklarında belirlenmiştir. Sonuçlar doğrultusunda üzüm salkım iskeletlerinin yüksek fenolik bileşik içerikleri sebebi ile gıda ya da gıda takviyesi olarak kullanılabileceği sonucuna varılmıştır.

Anahtar Kelimeler: Üzüm salkım iskeleti, Fenolik bileşik, Trans-resveratrol, Kateşin, Epikateşin

\section{ABSTRACT}

Grape seeds, skins and wine have been studied widely due to their beneficial effects on human health. However, there are only few studies from grape stems extracts. Therefore, the main objective of the present study was the assessment in stem extracts from 49 Vitis vinifera L. varieties of the total polyphenolic content (TPC), trans-resveratrol, catechin and epicatechin. The range of the TPC in grape stem extracts was from 17025 to $123250 \mathrm{mg}$ GAE $\mathrm{kg}^{-1}$ dry weight. Trans-resveratrol levels were range from 23.44 to 70.38 , catechin levels were range from 843 to 14144 and epicatechin levels were range from 0 to $981 \mathrm{mg} \mathrm{kg}^{-1} \mathrm{dry}$ weight. the present results indicate that grape stem extracts possess have important phenolic compounds, and thus they could be exploited, biofunctional foods or food supplements.

Key Words: Grape stem, Phenolic compound, Trans-resveratrol, Catechin, Epicatechin

\section{Giriş}

Vitis vinifera L. üzüm çeşitleri antik çağlardan beri insan beslenmesinin çok büyük bir parçası olmuştur. Dünyada 2018 yılında 74276583 ton üzüm üretilmiş, Türkiye 4200000 tonluk üretimi ile dünya sıralamasında 6. sırada yerini almıştır (FAO, 2019). Üzüm ürünleri eski zamanlardan itibaren içerdiği şeker ile beslenmede enerji kaynağı oluşturmasının yanı sıra son yıllarda insan sağlığına pozitif etkili bileşikler içermesiyle ilgili de çok sayıda araştırmaya konu olmuştur. Bu bileşiklerden özellikle trans-resveratrolün nörolojik-bilişsel performans hastalıkları, diyabet, kanser, kardiyovasküler hastalıklar, obezite, oksidatif strese bağlı hastalıklar ile otoimmün hastalıklar üzerine önleyici ve tedavi edici olduğunu ortaya koyan araştırmalar mevcuttur (Boocock ve ark., 2007; Yoshino ve ark., 2012; Del Rio ve ark., 2013; Gambini ve ark., 2015; Martínez-Huélamo, 
2016; Ramírez-Garza ve ark., 2018). Bahsi geçen faydalı etkileri sebebiyle toplumun üzüm çekirdeği vb. ekstraktlara ve gıda takviyelerine yönelimi artmıştır (Apostolou ve ark., 2013).

Üzümün içerdiği trans-resveratrol ile ilgili çalışmalar çoğunlukla çekirdek ve kabuk üzerine yoğunlaşmasına rağmen salkım iskeleti de göz ardı edilemeyecek bir trans-resveratrol kaynağıdır. Üzüm salkımlarının yaklaşık \%5'ini (h/h) oluşturan salkım iskeletleri üzerine gerçekleştirilmiş çok az sayıda araştırma bulunmaktadır. Apostolou ve ark. (2013) kırmızı renkli üzüm çeşitlerine ait trans-resveratrol içeriklerini 4.85 ile $20.56 \mathrm{mg} \mathrm{g}^{-1}$ aralığında belirlemiş ve salkım iskeletlerinin çekirdek kadar değerli bir antioksidan kaynağı olduğundan bahsetmiştir.

Meyve suyu ve vinifikasyon proseslerinin en önemli artıklarından olan salkım iskeletleri ülkemizde ve dünyada genellikle hayvan yemi, gübre ya da kompost eldesi amaciyla kullanılmaktadır. Ancak son yıllarda önemli bir sanayi artığı olan salkım iskeletleri içerdikleri fenolik bileşikler sebebiyle "Antioksidan içerikli diyet lifi olarak kullanılabilir mi?" sorusu gündeme gelmiştir.

$\mathrm{Bu}$ araştırmanın temel amacı salkım iskeletlerinin katma değeri yüksek bir ürüne dönüştürebilmesinin mümkün olacağı fikrinden yola çıkarak fenolik bileşik içeriklerinin belirlenmesidir. Bu amaçla 7 adet sofralık (Alphonse Lavallée, Cardinal,Crimson Seedless, Flame Seedless, Hamburg Misketi, Horoz Karası, Trakya ilkeren) ve 10 adet şaraplık (Boğazkere, Cabernet Sauvignon, Çal Karası, Kalecik Karası, Köhnü, Merlot, Nero d'Avola, Öküzgözü, Pinot Noir, Syrah) kırmızı üzüm çeşidinin salkım iskeletlerinde toplam fenolik bileşik, transresveratrol, kateşin ve epikateşin miktarları belirlenmiştir.

\section{Materyal ve Yöntem}

Araştırmada bitkisel materyal olarak farklı bölgelerden alınan sofralık ve şaraplık üzüm çeşitlerine ait (Vitis vinifera L.) salkım iskeletleri kullanılmıştır. Alphonse Lavallée üzüm çeşidi Efemçukuru İzmir, Kalecik Ankara ve
Tekirdağ'dan; Boğazkere üzüm çeşidi Denizli, Elazığ, Kalecik Ankara, Tekirdağ ve Urla İzmir'den; Cabernet Sauvignon üzüm çeşidi Beypazarı Ankara, Denizli, Efemçukuru İzmir, Elazığ,Kalecik Ankara, Tekirdağ ve Urla İzmir'den; Cardinal üzüm çeşidi Kalecik Ankara ve Tekirdağ'dan; Çal Karası üzüm çeşidi Denizli'den; Crimson Seedless üzüm çeşidi Kalecik Ankara'dan; Flame Seedless üzüm çeşidi Kalecik Ankara'dan; Hamburg Misketi üzüm çeşidi Kalecik Ankara ve Tekirdağ'dan; Köhnü üzüm çeşidi Elazığ ve Kalecik Ankara'dan; Merlot üzüm çeşidi Beypazarı Ankara, Denizli, Efemçukuru İzmir, Elazığ,Kalecik Ankara, Tekirdağ ve Urla İzmir'den; Nero d'Avola üzüm çeşidi Urla İzmir'den; Öküzgözü üzüm çeşidi Denizli, Elazığ,Kalecik Ankara, Tekirdağ'dan; Pinot Noir üzüm çeşidi Kalecik Ankara'dan; Red Globe çeşidi Kalecik Ankara'dan; Syrah üzüm çeşidi Efemçukuru İzmir, Kalecik Ankara, Tekirdağ ve Urla İzmir'den; ve Trakya İlkeren üzüm çeşidi ise Kalecik Ankara ile Tekirdağ'dan temin edilmiştir. Sofralık üzüm çeşitleri 18 briks kuru madde, şaraplık üzüm çeşitleri 24 briks kuru maddeye ulaştıkları teknolojik olgunluk dönemlerinde hasat edilerek Ankara Üniversitesi Ziraat Fakültesi Bahçe Bitkileri Bölümü'ne ulaştırılmıştır. Salkım iskeletleri tanelerinden ayrılarak bistüri yardımıyla parçalara ayrılarak $-80^{\circ} \mathrm{C}^{\prime}$ de dondurulmuşlar sonrasında 72 saat süreyle liyofilizasyona tabi tutularak (Labconco Freezone 2.5 Liter, USA) $0.5 \mathrm{~g}$ ağırlığında tartılmışlardır.

Fenolik bileşiklerin salkım iskeletlerinden ekstraksiyonu Waterhouse'a (2005) göre gerçekleştirilmiştir. Toplam fenolik bileşik analizleri UV-Vis spektrofotometre cihazı (Shimadzu Corporation, Japan) ile Singletton ve Rossi'ye (1965) göre yapılmış, sonuçlar mg Gallik Asit (GA) kg-1 olarak, kuru ağırlık (KA) cinsinden ifade edilmiştir. HPLC-DAD analizlerinde kullanılmak üzere ekstraksiyon işlemine devam edilmiştir. Salkım iskeletlerine ait ekstraktlar önce $0.45 \mu m^{\prime}$ lik PVDF (Sartorius, Goettingen, Germany) filtrelerden geçirilmiş, daha sonra "Agilent"marka "SampliQ 12 spe Manifold" modelvakum manifoldu kullanılarakkartuş şartlandırma işlemi gerçekleştirilmiştir ve bu amaçla "Waters" marka $1 \mathrm{~mL}$ hacimli $\mathrm{C}_{18}$ Seppak 
kartuşlar (Waters, Milford, MA, U.S.A.) kullanılmıştır. Sırasıyla $5 \mathrm{~mL}$ etil asetat, $5 \mathrm{~mL}$ metanol/hidroklorik asit (99.99/0.01; h/h), $1 \mathrm{~mL}$ ekstrakt, $5 \mathrm{~mL}$ etil asetat seppak kartuşlardan geçirilmiş, elde edilen ekstrakt azot gazı altında $40^{\circ} \mathrm{C}^{\prime}$ de kurutulmuş (Turbo Vap LV, Caliper, Hopkinton, MA, USA), sonrasında ise $2 \mathrm{~mL}$ hidroklorik asit (saf su/Hidroklorik asit; 99.99/0.01; h/h) ilavesi ile ultrasonik banyo yardımıyla fenolik bileşikler alınmıştır. Elde edilen ekstraktlar $0.45 \quad \mu m^{\prime} l i k \quad$ PVDF filtrelerden geçirilerek okumalara kadar amber renkliviallerde saklanmışlardır.

Salkım iskeletlerinde (-)-epikateşin, (+)-kateşin ve trans- resveratrol düzeyleri DAD detektör donanımlıHPLC cihazı ile belirlenmiştir (Shimadzu LC 10 AT VP). Fenolik bileşiklerin tanısı kullanılan standart maddelerin alıkonma zamanları ve spektrumlarından yararlanılarak yapılmıştır. Miktar tayininde fenolik bileşik standartlarına ait farklı konsantrasyonda $(50,15,12,9,6,3,1$ ppm) çözelti hazırlanarak HPLC'ye enjekte edilmiş ve standart eğrileri oluşturularak bu eğrilerden fenolik bileşiklerin miktarları hesaplanmıştır. Fenolik bileşiklerin miktarsal doğruluk oranlarının artırıması amaçlı geri kazanım oranı, dedeksiyon ve kuantifikasyon limitleri de hesaplanmıştır. Çizelge 1'de HPLC cihazının çalışma koşulları, Çizelge 2'de fenolik bileşik miktarlarının belirlenmesinde kullanılan kalibrasyon parametreleri verilmiştir. Sonuçlar $\mathrm{mg} \mathrm{kg}^{-1} \mathrm{KA}$ olarak ifade edilmiştir.

Çizelge 1. HPLC-DAD cihazının çalışma koşulları Table 1. HPLC-DAD conditions

\begin{tabular}{ll}
\hline $\begin{array}{l}\text { HPLC kolonu } \\
\text { HPLC Column }\end{array}$ & Phenomenex Gemini 260x4.60 \\
\hline $\begin{array}{l}\text { Enjekte edilen miktar } \\
\text { Injection amount }\end{array}$ & $30 \mu \mathrm{L}$ \\
\hline Taşıуıc faz & A: Su/ Formik asit $(99 / 1: \mathrm{h} / \mathrm{h}) \mathrm{B}:$ \\
$\begin{array}{l}\text { Mobile phase } \\
\text { Akış hızı } \\
\text { Flow rate }\end{array}$ & Asetonitril $(100 / 100: \mathrm{h} / \mathrm{h})$ \\
\hline $\begin{array}{l}\text { Kolon sıcaklığı } \\
\text { Column temperature }\end{array}$ & $0.7 \mathrm{mLdk}^{-1}$ \\
\hline
\end{tabular}

Çizelge 2. HPLC-DAD cihazı ile fenolik bileşiklerin belirlenmesinde kullanılan kalibrasyon parametreleri Table 2. Calibration parameters used for the HPLC-DAD determination of phenolic compounds

\begin{tabular}{|c|c|c|c|c|c|c|}
\hline $\begin{array}{l}\text { Fenolik } \\
\text { bileşikler } \\
\text { Phenolic } \\
\text { compounds }\end{array}$ & $\begin{array}{l}\text { Alıkonma zamanı } \\
\text { (dakika) } \\
\text { Retention time } \\
\text { (min) }\end{array}$ & $\lambda(\mathrm{nm})$ & $\begin{array}{l}\text { Kalibrasyon } \\
\text { denklemi } \\
\text { Calibration } \\
\text { curve }\end{array}$ & $\mathrm{R}^{2}$ & $\begin{array}{l}\text { Dedeksiyon } \\
\text { limiti } \\
\left(\mathrm{mg} \mathrm{kg}^{-1}\right) \\
\text { Limit of } \\
\text { detection }\end{array}$ & $\begin{array}{l}\text { Kuantifikasyon } \\
\text { limiti } \\
\left(\mathrm{mg} \mathrm{kg}^{-1}\right) \\
\text { Limit of } \\
\text { quantification }\end{array}$ \\
\hline $\begin{array}{l}(+) \text { - kateşin } \\
(+) \text { - catechin }\end{array}$ & 28.6 & 280 & $y=15323 x-160$ & 0.9997 & 0.96 & 2.91 \\
\hline $\begin{array}{l}\text { (-)- epikateşin } \\
\text { (-)-epicatechin }\end{array}$ & 33.7 & 280 & $y=33977 x-7173$ & 0.9999 & 0.69 & 2.09 \\
\hline $\begin{array}{l}\text { trans- resveratrol } \\
\text { trans- resveratrol }\end{array}$ & 54.9 & 306 & $y=403404 x-78716$ & 0.9998 & 0.28 & 0.86 \\
\hline
\end{tabular}

$\lambda$, dalga boyu; $R^{2}$, korelasyon katsayıları

$\lambda$, wavelength; $R^{2}$, correlation coefficients

Araştırma sonucunda elde edilen sayısal değerler SPSS (SPSS Inc.,Chicago, Illinois) istatistik programı (11.5) kullanılarak değerlendirilmiş, farklııkların önem düzeyini belirlemek için Duncan testi kullanılmıştır. Sonuçlar ortalama \pm ortalamanın standart hatası olarak ifade edilmiştir.

\section{Araştırma Bulguları ve Tartışma}

Üzüm çeşitlerine ait salkım iskeletlerinin toplam fenolik bileşik (TFB) düzeyleri

Salkım iskeletlerinin toplam fenolik bileşik içerikleri Çizelge 3'te verilmiştir. İzmir, Ankara ve
Tekirdağ'dan temin edilen Alphonse Lavallée çeşidine ait salkım iskeletlerinin toplam fenolik bileşik içerikleri (TFB) $61500 \mathrm{mg} \mathrm{GAE} \mathrm{kg}{ }^{-1} \mathrm{KA}$ ile 107300 mg GAE kg ${ }^{-1}$ KA arasında; Denizli, Elazığ, Ankara, Tekirdağ ve İzmir'den temin edilen Boğazkere çeşidinin TFB içerikleri 46650 mg GAE $\mathrm{kg}^{-1} \mathrm{KA}$ ile $113500 \mathrm{mg}$ GAE kg ${ }^{-1} \mathrm{KA}$ arasında; Beypazarı Ankara, Denizli, Efemçukuru İzmir, Elazığ, Kalecik Ankara, Tekirdağ ve Urla İzmir'den temin edilen Cabernet Sauvignon çeşidinin TFB içerikleri $37800 \mathrm{mg} \mathrm{GAE} \mathrm{kg}^{-1} \mathrm{KA}$ ile $84500 \mathrm{mg} \mathrm{GAE}$ $\mathrm{kg}^{-1} \mathrm{KA}$ arasında; Ankara ve Tekirdağ'dan temin edilen Cardinal çeşidinin TFB içerikleri 95700 mg GAE kg ${ }^{-1} \mathrm{KA}$ ile 109000 mg GAE kg ${ }^{-1} \mathrm{KA}$ arasında; 
Denizli'den temin edilen Çal Karası çeşidinin TFB içeriği 56450 mg GAE kg-1 KA; Kalecik Ankara'dan temin edilen Crimson Seedless, Flame Seedless, Horoz Karası, Pinot Noir ve Red Globe çeşitlerinin TFB içerikleri sırasıyla $84100 \mathrm{mg} \mathrm{GAE} \mathrm{kg}{ }^{-1} \mathrm{KA}, 44$ $400 \mathrm{mg} \mathrm{GAE} \mathrm{kg}{ }^{-1} \mathrm{KA}, 111600 \mathrm{mg} \mathrm{GAE} \mathrm{kg}^{-1} \mathrm{KA}, 40$

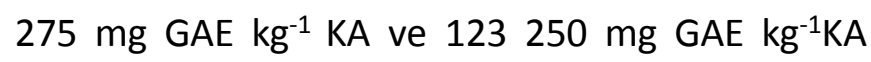
olarak belirlenmiştir. Ankara ve Tekirdağ'dan temin edilen Hamburg Misketi çeşidinin TFB içeriği 74 $450 \mathrm{mg}$ GAE kg ${ }^{-1} \mathrm{KA}$ ile $83300 \mathrm{mg}$ GAE kg-1 KA olarak; Beypazarı Ankara, Elmalı Antalya, Kalecik Ankara ve Tekirdağ'dan temin edilen Kalecik Karası çeşidini TFB içerikleri $33150 \mathrm{mg} \mathrm{GAE} \mathrm{kg}{ }^{-1} \mathrm{KA}$ ile 43 550 mg GAE kg-1 KA değerleri arasında; Elazığ ve Kalecik'ten temin edilen Köhnü çeşidinin TFB içerikleri sırasıyla 63650 mg GAE kg-1 KA ile 79100 mg GAE kg-1 KA değerlerinde; Beypazarı Ankara, Denizli, Efemçukuru İzmir, Elazığ, Kalecik Ankara, Tekirdağ, Urla İzmir'den temin edilen Merlot çeşidinin TFB değerleri 34950 mg GAE kg-1 KA ile 58850 mg GAE kg-1 KA değerleri arasında; Urla İzmir'den temin edilen Nero d'Avola çeşidinin TFB değeri 52050 mg GAE kg-1 KA; Denizli, Elazığ, Kalecik Ankara ve Tekirdağ'dan temin edilen Öküzgözü çeşidinin TFB değerleri 45400 mg GAE $\mathrm{kg}^{-1} \mathrm{KA}$ ile $98450 \mathrm{mg} \mathrm{GAE} \mathrm{kg}{ }^{-1} \mathrm{KA}$ değerleri arasında; Efemçukuru İzmir, Kalecik Ankara, Tekirdağ ve Urla İzmir'den temin edilen Syrah çeşidinin TFB değerleri 24075 mg GAE kg-1 KA ile $63825 \mathrm{mg} \mathrm{GAE} \mathrm{kg}^{-1} \mathrm{KA}$ değerleri arasında ve son olarak Ankara ve Tekirdağ'dan temin edilen Trakya Illkeren çeşidinin TFB içerikleri 110175 mg GAE kg-1 KA ile 96825 mg GAE kg-1 KA olarak belirlenmiştir.

Farklı bölgelerden temin edilen çeşitler arasında en düşük TFB içeriği Kalecik Karası (Elmalı-Antalya) çeşidinde $17025 \mathrm{mg}$ GAE kg-1 KA olarak belirlenmişken, en yüksek değer bu değerden yaklaşık 7.2 kat daha fazla olarak Red Globe (Kalecik-Ankara) çeşidinde belirlenmiştir. VázquezArmenta ve ark., (2017) Red Globe çeşidinin salkım iskeletlerinde TFB değerini 3725 mg GAE kg-1 YA (yaş ağırlık) olarak ölçülmüştür. Bir başka araştırmada Yunanistan kırmızı üzüm çeşitlerine ait salkım iskeletlerindeki TFB değerleri 345 000-584

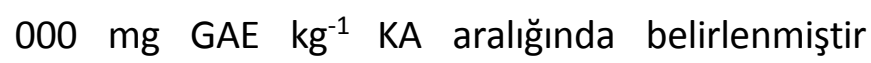
(Apostolou ve ark., 2013).
Çizelge 3. Farklı bölgelerden temin edilen üzüm çeşitlerine ait salkım iskeletlerinin toplam fenolik bileşik içerikleri (mg GAE kg-1 KA).

Table 3. Total phenolic compound contents of grape varieties obtained from different regions ( $m g$ GAE $\left.k g^{-1} D W\right)$.

\begin{tabular}{|c|c|c|}
\hline Çeşit & Bölge & Toplam Fenolik \\
\hline \multirow{3}{*}{ Variety } & Region & Bileşik \\
\hline & & Total Phenolic \\
\hline & & Compound \\
\hline \multirow[t]{3}{*}{ Alphonse Lavallée } & Efemçukuru İzmir & $61500 \pm 275 \mathrm{~b}$ \\
\hline & Kalecik Ankara & $107300 \pm 250 \mathrm{a}$ \\
\hline & Tekirdağ & $61900 \pm 550 \mathrm{~b}$ \\
\hline \multirow[t]{5}{*}{ Boğazkere } & Denizli & $113500 \pm 2350 a$ \\
\hline & Elazı̆g & $46650 \pm 1100 d$ \\
\hline & Kalecik Ankara & $93300 \pm 50 \mathrm{~b}$ \\
\hline & Tekirdağ & $47450 \pm 300 \mathrm{~d}$ \\
\hline & Urla İzmir & $62550 \pm 1000 \mathrm{c}$ \\
\hline \multirow{7}{*}{$\begin{array}{l}\text { Cabernet } \\
\text { Sauvignon }\end{array}$} & Beypazarı Ankara & $47850 \pm 575 \mathrm{bc}$ \\
\hline & Denizli & $47450 \pm 900 \mathrm{bc}$ \\
\hline & Efemçukuru İzmir & $45825 \pm 450 \mathrm{c}$ \\
\hline & Elazığ & $41550 \pm 1100 \mathrm{~d}$ \\
\hline & Kalecik Ankara & $49750 \pm 1300 \mathrm{~b}$ \\
\hline & Tekirdağ & $84500 \pm 750 a$ \\
\hline & Urla İzmir & $37800 \pm 950$ e \\
\hline \multirow[t]{2}{*}{ Cardinal } & Kalecik Ankara & $109000 \pm 950 \mathrm{a}$ \\
\hline & Tekirdağ & $95700 \pm 2475 \mathrm{~b}$ \\
\hline Çal Karası & Denizli & $56450 \pm 1300$ \\
\hline Crimson Seedless & Kalecik Ankara & $84100 \pm 2050 \mathrm{a}$ \\
\hline Flame Seedless & Kalecik Ankara & $44400 \pm 450 \mathrm{c}$ \\
\hline \multirow[t]{2}{*}{ Hamburg Misketi } & Kalecik Ankara & $83300 \pm 50 \mathrm{a}$ \\
\hline & Tekirdağ & $74450 \pm 100 \mathrm{~b}$ \\
\hline Horoz Karası & Kalecik Ankara & $111600 \pm 1150$ \\
\hline \multirow[t]{4}{*}{ Kalecik Karası } & Beypazarı Ankara & $33150 \pm 700 \mathrm{c}$ \\
\hline & Elmalı Antalya & $17025 \pm 200 d$ \\
\hline & Kalecik Ankara & $37850 \pm 400 \mathrm{~b}$ \\
\hline & Tekirdağ & $43550 \pm 0.0 \mathrm{a}$ \\
\hline \multirow[t]{2}{*}{ Köhnü } & Elazığ & $63650 \pm 2000 \mathrm{~b}$ \\
\hline & Kalecik Ankara & $79100 \pm 3150 \mathrm{a}$ \\
\hline \multirow[t]{7}{*}{ Merlot } & Beypazarı Ankara & $48650 \pm 1600 \mathrm{~d}$ \\
\hline & Denizli & $34950 \pm 1275 \mathrm{e}$ \\
\hline & Efemçukuru İzmir & $58850 \pm 1200 \mathrm{~b}$ \\
\hline & Elazığ & $64250 \pm 500 a$ \\
\hline & Kalecik Ankara & $54400 \pm 450 \mathrm{c}$ \\
\hline & Tekirdağ & $56125 \pm 600 \mathrm{bc}$ \\
\hline & Urla İzmir & $46300 \pm 1050 \mathrm{~d}$ \\
\hline Nero d'Avola & Urla İzmir & $52050 \pm 1300 \mathrm{~b}$ \\
\hline \multirow[t]{4}{*}{ Öküzgözü } & Denizli & $98450 \pm 2800 \mathrm{a}$ \\
\hline & Elazığ & $47100 \pm 1150 \mathrm{c}$ \\
\hline & Kalecik Ankara & $66300 \pm 50 \mathrm{~b}$ \\
\hline & Tekirdağ & $45400 \pm 350 \mathrm{c}$ \\
\hline Pinot Noir & Kalecik Ankara & $40275 \pm 800$ \\
\hline Red Globe & Kalecik Ankara & $123250 \pm 200$ \\
\hline \multirow[t]{4}{*}{ Syrah } & Efemçukuru İzmir & $63825 \pm 2350 a$ \\
\hline & Kalecik Ankara & $27400 \pm 225 c$ \\
\hline & Tekirdağ & $51450 \pm 300 \mathrm{~b}$ \\
\hline & Urla İzmir & $24075 \pm 0 \mathrm{c}$ \\
\hline \multirow[t]{2}{*}{ Trakya Illkeren } & Kalecik Ankara & $110175 \pm 750 \mathrm{a}$ \\
\hline & Tekirdağ & $96825 \pm 0 \mathrm{~b}$ \\
\hline
\end{tabular}

Aynı sütundaki farklı harfler istatistiksel olarak $p<0.05$ düzeyinde önemlidir

Different letters in the same column indicate statistical differences at the $p<0.05$ level. 
TFB düzeyi trans-resveratrol, kateşin, epikateşin ve tanenler de dahil olmak üzere üzüm polifenollerinin toplamını yansıtmaktadır. Salkım iskeletlerine ait TFB sonuçları etkileyici derecede yüksek düzeyde belirlenmiştir ve bu sonuç salkım iskeletlerinin çok iyi birer biyoaktif polifenol kaynağı olabileceğini düşündürtmüştür. $\mathrm{Bu}$ çıkarım önceki araştırmalarla da paraleldir (Spigno ve De Faveri, 2007; Vázquez-Armenta, 2017).

Üzüm çeşitlerine ait salkım iskeletlerinin transresveratrol, kateşin ve epikateşin düzeyleri

Salkım iskeletlerinin trans-resveratrol, kateşin ve epikateşindüzeyleriÇizelge 4 'te verilmiştir. Araştırma sonuçlarına örneklerin göre transresveratrol içerikleri $23.44 \mathrm{mg} \mathrm{kg}^{-1} \mathrm{KA}$ ile $70.38 \mathrm{mg}$ $\mathrm{kg}^{-1} \mathrm{KA}$ aralığında değişiklik göstermiştir. En yüksek trans-resveratrol içeriği Kalecik Karası (Tekirdağ) çeşidinde, en düşük trans-resveratrol içeriği ise Boğazkere (Kalecik Ankara) çeşidinde ölçülmüştür. Kalecik Karası'nı sırasıyla; Syrah ve Merlot çeşitleri takip etmiştir. Kırmızı üzüm çeşitlerine ait salkım iskeletlerinin trans-resveratrol düzeyleri kuru örneklerde çalışılan önceki araştırmalarda 1 756-5 $470 \mathrm{mg} \mathrm{kg}^{-1} \mathrm{KA}$ (Apostolou ve ark., 2013) ve 87.8$266 \mathrm{mg} \mathrm{kg}^{-1} \mathrm{KA}$ (Anastasiadi ve ark., 2012) aralıklarında belirlenmiştir.

Kateşin içerikleri 843 (Öküzgözü-Denizli) ile 14 $144 \mathrm{mg} \mathrm{kg}{ }^{-1}$ KA (Red Globe- Kalecik Ankara) aralığında, epikateşin içerikleri ise 0 (Syrah) ile 981 mg kg-1 KA (Hamburg Misketi-Kalecik Ankara) aralığında değişiklik göstermiştir. Kateşin içeriği en yüksek Red Globe çeşidinde belirlenmiş, bu çeşidi sırasıyla Cardinal ve Alphonse Lavallée çeşitleri izlemiştir.

Epikateşin düzeyleri ise sırası ile Hamburg Misketi, Pinot Noir ve Çal Karası çeşitlerinde en yüksek değerdedir. trans-resveratrol düzeyi Tekirdağ'dan temin edilen çeşitlerde en yüksek belirlenirken, TFB, kateşin ve epikateşin Kalecik Ankara'dan temin edilen çeşitlerde yüksek olarak bulunmuştur. Apostolou ve ark. (2013) kırmızı çeşitlerin salkım iskeletlerinde kateşin düzeylerinin 8 490-85 $810 \mathrm{mg} \mathrm{kg}^{-1} \mathrm{KA}$ aralığında, epikateşin düzeylerinin ise 0-11 $140 \mathrm{mg} \mathrm{kg}^{-1} \mathrm{KA}$ aralığında olduğunu söylemişlerdir.
Surguladze ve Bezhuashvili (2017) tentüriye bir çeşit olan Spaeravi üzüm çeşidinin şaraba işleme sonrası salkım iskeletlerinde trans-resveratrol

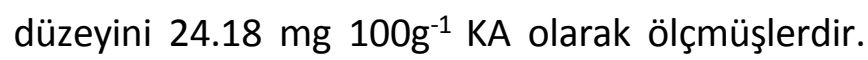
Bir başka araştırmada ise kırmızı üzüm cibrelerinde toplam fenolik bileşik içerikleri 19.1-50.9 $\mathrm{mg} \mathrm{g}^{-1} \mathrm{KA}$, kateşin 589-1 907.5 $\mathrm{mg} \mathrm{g}^{-1} \mathrm{KA}$, rutin 84.6-153.7 mg

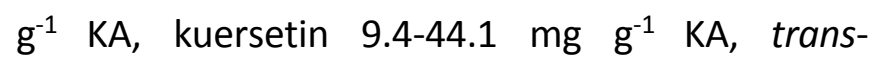
resveratrol 0-1.4 $\mathrm{mg} \quad \mathrm{g}^{-1} \quad \mathrm{KA}$ aralıklarında ölçülmüştür (Martins ve ark., 2016). Araştırmamızda incelenen parametreler hasat sonrası salkım iskeletlerinde gerçekleştirilmiştir. Bahsi geçen önceki çalışmalar ise cibrelerde ölçülen fenolik bileşik değerleridir.Araştırmamıza konu olan salkım iskeletlerinin cibrelerdeki fenolik bileşik içeriklerinin de yüksek miktarda tespit edilmiş olması salkım iskeletlerinin antioksidan değeri açısından, sonuçlarımızı destekleyici niteliktedir.

Fenolik bileşiklerin miktarları yetiştiricilik koşulları, çeşit farklııkları ve iklim özelliklerinin yanı sıra ekstraksiyon yöntemlerine göre de değişiklik göstermektedir. Kullanılan çözücü solüsyonlar ekstraktlardaki fenolik bileşik içeriklerini etkilemektedir. Araştırma sonuçlarına göre çeşitlerin salkım iskeletleri fenolik bileşikler açısından yoğundur ve salkım iskeletleri de kolay ulaşılabilir sanayi artıkları olduklarından pahalı olmayan ve değerlendirilebilir fenolik bileşik kaynağı olabilmektedirler.

Üzüm fenoliklerinin reaktif oksijen türlerinin neden olduğu DNA hasarını önlediği önceki çalışmalarla kanıtlanmıştır (Stagos ve ark., 2006) aynı zamanda Che ve ark. (2017) gerçekleştirdikleri bir araştırmada Campbell Early çeşidine ait salkım iskeleti ekstraktlarının, fenolik bileşik içerikleri sayesinde UV kaynaklı cilt hasarını engelleyici özellikte olduğunu söylemişlerdir. Literatürdeki bu verilere ve araştırma sonuçlarına rağmen üzüm ürünleri işleyen sanayi artıklarında geniş hacme sahip salkım iskeletleri katma değerli bir ürüne dönüştürülmemektedir. Oysa ki salkım iskeletleri flavonoidler, stilbenler ve fenolik asitler gibi biyoaktif polifenoller bakımından zengindir ve yüksek polifenol kaynağı olarak kullanılabilir özelliktedirler. 
Çizelge 4. Farklı bölgelerden temin edilen üzüm çeşitlerine ait salkım iskeletlerinin trans-resveratrol, kateşin ve epikateşiniçerikleri ( $\left.\mathrm{mg} \mathrm{kg}^{-1} \mathrm{KA}\right)$.

Table 4. trans-resveratrol, catechin and epicatechin contents of grape varieties obtained from different regions (mg kg-1 DW).

\begin{tabular}{|c|c|c|c|c|}
\hline $\begin{array}{l}\text { Çeşit } \\
\text { Variety }\end{array}$ & $\begin{array}{l}\text { Bölge } \\
\text { Region }\end{array}$ & $\begin{array}{l}\text { Trans-resveratrol } \\
\text { Trans-resveratrol }\end{array}$ & $\begin{array}{l}\text { Kateşin } \\
\text { catechin }\end{array}$ & $\begin{array}{l}\text { Epikateşin } \\
\text { epicatechin }\end{array}$ \\
\hline \multirow[t]{3}{*}{ Alphonse Lavallée } & Efemçukuru İzmir & $27.3 \pm 0.2 \mathrm{~b}$ & $7022 \pm 169 \mathrm{~b}$ & $134 \pm 2.4 \mathrm{a}$ \\
\hline & Kalecik Ankara & $33.9 \pm 1.1 \mathrm{a}$ & $10472 \pm 124 a$ & $85 \pm 0.9 b$ \\
\hline & Tekirdağ & $35.3 \pm 0.1 \mathrm{a}$ & $5305 \pm 22 c$ & $68 \pm 5.4 \mathrm{c}$ \\
\hline \multirow[t]{5}{*}{ Boğazkere } & Denizli & $27.3 \pm 0.1 \mathrm{c}$ & $1113 \pm 20 \mathrm{c}$ & $162 \pm 0.8 \mathrm{a}$ \\
\hline & Elazığ & $28.1 \pm 0.0 \mathrm{~b}$ & $1518 \pm 12 b c$ & $67 \pm 0.8 d$ \\
\hline & Kalecik Ankara & $23.4 \pm 0.0 \mathrm{~d}$ & $4792 \pm 176 \mathrm{a}$ & $104 \pm 0.7 \mathrm{c}$ \\
\hline & Tekirdağ & $27.2 \pm 0.1 \mathrm{c}$ & $2438 \pm 9 b$ & $111 \pm 2.8 b$ \\
\hline & Urla İzmir & $30.2 \pm 0.3 \mathrm{a}$ & $1995 \pm 591 \mathrm{bc}$ & $0.0 \pm 0.0 \mathrm{e}$ \\
\hline \multirow[t]{7}{*}{ Cabernet Sauvignon } & Beypazarı Ankara & $26.8 \pm 0.0 \mathrm{c}$ & $4236 \pm 131 b$ & $165 \pm 5.5 \mathrm{a}$ \\
\hline & Denizli & $43.2 \pm 0.0 \mathrm{a}$ & $3062 \pm 41 \mathrm{~cd}$ & $122 \pm 0.6 \mathrm{~cd}$ \\
\hline & Efemçukuru İzmir & $31.1 \pm 0.7 b$ & $3844 \pm 267 b$ & $133 \pm 5.2 \mathrm{~b}$ \\
\hline & 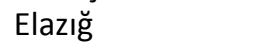 & $27.3 \pm 0.1 c$ & $4214 \pm 51 \mathrm{~b}$ & $100 \pm 0.6 \mathrm{e}$ \\
\hline & Kalecik Ankara & $24.3 \pm 0.0 \mathrm{~d}$ & $2756 \pm 19 d$ & $114 \pm 0.3 d$ \\
\hline & Tekirdağ & $31.7 \pm 0.3 b$ & $4797 \pm 23 a$ & $121 \pm 0.7 \mathrm{~cd}$ \\
\hline & Urla İzmir & $26.6 \pm 0.2 c$ & $3216 \pm 44 \mathrm{c}$ & $126 \pm 1.5 \mathrm{bc}$ \\
\hline \multirow[t]{2}{*}{ Cardinal } & Kalecik Ankara & $25.4 \pm 0.1 \mathrm{~b}$ & $12529 \pm 428 \mathrm{a}$ & $32 \pm 1.8 \mathrm{~b}$ \\
\hline & Tekirdağ & $43.1 \pm 0.3 \mathrm{a}$ & $8824 \pm 161$ b & $156 \pm 2.1 \mathrm{a}$ \\
\hline Çal Karası & Denizli & $31.3 \pm 0.2$ & $3194 \pm 5$ & $199 \pm 99.3$ \\
\hline Crimson Seedless & Kalecik Ankara & $24.4 \pm 0.1$ & $6809 \pm 128$ & $90 \pm 0.1$ \\
\hline Flame Seedless & Kalecik Ankara & $23.7 \pm 0.4$ & $2934 \pm 531$ & $52 \pm 5.8$ \\
\hline \multirow[t]{2}{*}{ Hamburg Misketi } & Kalecik Ankara & $25.4 \pm 0.1 \mathrm{~b}$ & $6653 \pm 52 a$ & $981 \pm 2.4 \mathrm{a}$ \\
\hline & Tekirdağ & $45.7 \pm 0.3 \mathrm{a}$ & $6258 \pm 45 b$ & $107 \pm 1.4$ \\
\hline Horoz Karası & Kalecik Ankara & $24.6 \pm 0.0 \mathrm{~b}$ & $9762 \pm 280$ & $0.0 \pm 0.0$ \\
\hline \multirow[t]{4}{*}{ Kalecik Karası } & Beypazarı Ankara & $24.8 \pm 0.1 b$ & $1617 \pm 9 \mathrm{c}$ & $70 \pm 1.0 \mathrm{~b}$ \\
\hline & Elmalı Antalya & $27.3 \pm 0.2 b$ & $1617 \pm 9 \mathrm{c}$ & $0.0 \pm 0.0 \mathrm{c}$ \\
\hline & Kalecik Ankara & $25.2 \pm 0.3 b$ & $2171 \pm 40 \mathrm{~b}$ & $0.0 \pm 0.0 \mathrm{c}$ \\
\hline & Tekirdağ & $70.3 \pm 1.1 \mathrm{a}$ & $3075 \pm 16 a$ & $76 \pm 0.0 \mathrm{a}$ \\
\hline \multirow[t]{2}{*}{ Köhnü } & Elazıı̆ & $35.4 \pm 0.4 \mathrm{a}$ & $1873 \pm 102 b$ & $89 \pm 3.8 b$ \\
\hline & Kalecik Ankara & $31.3 \pm 0.3 b$ & $4836 \pm 6$ a & $123 \pm 1.3 \mathrm{a}$ \\
\hline \multirow[t]{7}{*}{ Merlot } & Beypazarı Ankara & $27.1 \pm 0.3 \mathrm{~cd}$ & $4242 \pm 151 b$ & $124 \pm 2.3 \mathrm{~b}$ \\
\hline & Denizli & $27.6 \pm 0.2 c$ & $1433 \pm 10 \mathrm{e}$ & $77 \pm 1.7 \mathrm{c}$ \\
\hline & Efemçukuru İzmir & $38.3 \pm 0.2 \mathrm{~b}$ & $5123 \pm 97 a$ & $149 \pm 1.2 \mathrm{a}$ \\
\hline & Elazığ & $27.3 \pm 0.1 \mathrm{~cd}$ & $3743 \pm 47 c$ & $0.0 \pm 0.0 d$ \\
\hline & Kalecik Ankara & $25.2 \pm 0.3 \mathrm{de}$ & $2171 \pm 40 d$ & $0.0 \pm 0.0 \mathrm{~d}$ \\
\hline & Tekirdağ & $46.8 \pm 1.4 \mathrm{a}$ & $5126 \pm 127 \mathrm{a}$ & $145 \pm 2.9 \mathrm{a}$ \\
\hline & Urla İzmir & $24.9 \pm 0.0 \mathrm{e}$ & $1239 \pm 27 \mathrm{e}$ & $76 \pm 0.2 c$ \\
\hline Nero d'Avola & Urla İzmir & $40.9 \pm 1.2$ & $2946 \pm 115$ & $0.0 \pm 0.0$ \\
\hline \multirow[t]{4}{*}{ Öküzgözü } & Denizli & $31.9 \pm 0.2 b c$ & $843 \pm 25 c$ & $0.0 \pm 0.0 \mathrm{c}$ \\
\hline & Elazıı̆ & $35.9 \pm 1.6 \mathrm{~b}$ & $2218 \pm 79 a b$ & $125 \pm 3.5 \mathrm{a}$ \\
\hline & Kalecik Ankara & $42.8 \pm 1.8 \mathrm{a}$ & $2577 \pm 165$ a & $96 \pm 5.0 \mathrm{~b}$ \\
\hline & Tekirdağ & $29.4 \pm 0.7 c$ & $2148 \pm 19 b$ & $86 \pm 0.2 b$ \\
\hline Pinot Noir & Kalecik Ankara & $34.9 \pm 0.4$ & $4653 \pm 266$ & $298 \pm 15.916$ \\
\hline Red Globe & Kalecik Ankara & $27.9 \pm 0.0$ & $14144 \pm 270$ & $0.0 \pm 0.0$ \\
\hline \multirow[t]{4}{*}{ Syrah } & Efemçukuru İzmir & $38.1 \pm 1.1 \mathrm{~b}$ & $5874 \pm 170$ a & $106 \pm 0.5 \mathrm{a}$ \\
\hline & Kalecik Ankara & $45.7 \pm 3.4 \mathrm{~b}$ & $3469 \pm 432 b c$ & $0.0 \pm 0.0 \mathrm{~b}$ \\
\hline & Tekirdağ & $57.5 \pm 1.6 \mathrm{a}$ & $4388 \pm 122 b$ & $0.0 \pm 0.0 \mathrm{~b}$ \\
\hline & Urla İzmir & $61.5 \pm 0.4 \mathrm{a}$ & $2987 \pm 50 \mathrm{c}$ & $0.0 \pm 0.0 \mathrm{~b}$ \\
\hline \multirow[t]{2}{*}{ Trakya İlkeren } & Kalecik Ankara & $26.3 \pm 0.5 \mathrm{~b}$ & $10011 \pm 587 a$ & $125 \pm 8.7 \mathrm{a}$ \\
\hline & Tekirdağ & $43.1 \pm 0.4 \mathrm{a}$ & $8153 \pm 141 b$ & $117 \pm 5.8 \mathrm{~b}$ \\
\hline
\end{tabular}

Aynı sütundaki farklı harfler istatistiksel olarak $\mathrm{p}<0.05$ düzeyinde önemlidir

Different letters in the same column indicate statistical differences at the $p<0.05$ level.

\section{Sonuç ve Öneriler}

Üzüm çekirdek ve kabuklarında bulunan fenolik bileşikler sayesinde son yıllarda önemi anlaşılmış tarımsal ürünlerdendir. Bunun yanı sıra salkım iskeletleri de sağlığa yararlı fenolik bileşikler açısından zengindir. Üzüm fenoliklerinin antioksidan ve antimikrobiyal ajanlar olarak kullanımıyla ilgili çok sayıda çalışma bulunmasının yanı sıra, üzüm salkım iskeletlerinin değerlendirilmesinde ve gıda endüstrilerinde potansiyel kullanımlarında hala bir eksiklik söz konusudur. Araştırma salkım iskeletlerinin fitokimyasal bileşimi üzerine bir takım sonuçlar 
ortaya koymuş olmakla birlikte, bu çok önemli sanayi artığı ürünlerin potansiyel olarak biyolojik aktif madde olarak kullanılmasını destekleyici sonuca varmıştır. Böylece katma değeri olan bir yan ürün olarak salkım iskeletlerinin kullanılabilmesiyle ilgili yeni araştırmalara yol açmıştır. Özellikle üzüm suyu ve şarap endüstrisi artığı olan salkım iskeletlerinin sürdürülebilir ve yüksek katma değerli bir ürüne (kozmetik, gıda ve/veya farmasötik) dönüştürülebilmesi amacıyla yeni araştırmalar gerçekleştirilmelidir.

\section{Ekler}

"11B4347003" kod numaralı ve "Ülkemizde Yetiştirilen Asma Tür ve Çeşitlerinde Antioksidan, Resveratrol ve Diğer Fenolik Bileşiklerin Belirlenmesi Üzerinde Bir Araştırma" isimli projeye sağladığı destek için "Ankara Üniversitesi Bilimsel Araştırma Projeleri Koordinatörlüğü" ne teşekkürlerimizi sunarız.

\section{Çıkar Çatışması Beyanı: "Makale yazarları} aralarında herhangi bir çıkar çatışması olmadığını beyan ederler."

\section{Kaynaklar}

Anastasiadi, M., Pratsinis, H., Kletsas, D., Skaltsounis, A.L., Haroutounian, S. A. (2012). Grape stem extracts: Polyphenolic content and assessment of their in vitro antioxidant properties. LWT - Food Science and Technology, 48, 316-322.

Apostolou, A., Stagos, D., Galitsiou, E., Spyrou, A., Haroutounian, S., Portesis, N., Trizoglou, I., Hayes, A. W., Tsatsakis, A. M. \& Kouretas, D. (2013). Assessment of polyphenolic content, antioxidant activity, protection against ROS-induced DNA damage and anticancer activity of Vitis vinifera stem extracts. Food and Chemical Toxicology, 61, 60-68.

Boocock, D. J., Faust, G. E. S., Patel, K. R., Schinas, A. M., Brown, V. A., Ducharme, M. P., Booth, T. D., Crowell, J. A., Perloff, M., Gescher, A. J. (2007). Phase i dose escalation pharmacokinetic study in healthy volunteers of resveratrol, a potential cancer chemopreventive agent. Cancer Epidemiology Biomarkers and Preventetion, 16, 1246-1253.

Che, D. N., Xie, G. H., Cho, B. O., Shin, J. Y., Kang, H. J., Jang, S. I. (2017). Protective effects of grape stem extract against UVB-induced damage in C57BL mice skin. Journal of Photochemistry and Photobiology B: Biology, 173, 551-559.

Del Rio, D., Rodriguez-Mateos, A., Spencer, J. P. E., Tognolini, M., Borges, G., Crozier, A. (2013). Dietary (Poly)phenolics in Human Health: Structures,
Bioavailability, and Evidence of Protective Effects Against Chronic Diseases. Antioxidants and Redox Signaling, 18, 1818-1892.

FAO (2019). Statistical data of FAO. Retrieved from: http://www.fao.org/faostat/en/.

Gambini, J., Inglés, M., Olaso, G., Lopez-Grueso, R., BonetCosta, V., Gimeno-Mallench, L., Mas-Bargues, C., Abdelaziz, K.M., Gomez-Cabrera, M. C., Vina, J., Borras, C. (2015). Properties of resveratrol: In vitro and in vivo studies about metabolism, bioavailability, and biological effects in animal models and humans. Oxidative Medicine and Cellular Longevity, 2015, 837042.

Martínez-Huélamo, M., Vallverdú-Queralt, A., Di Lecce, G., Valderas-Martínez, P., Tulipani, S., Jáuregui, O., Escribano-Ferrer, E., Estruch, R., Illan, M., LamuelaRaventós, R. M. (2016). Bioavailability of tomato polyphenols is enhanced by processing and fat addition: Evidence from a randomized feeding trial. Molecular Nutrition and Food Research,60, 15781589.

Martins, I. M., Roberto, B.S., Blumberg, J. B., Chen, C.-Y. O., Macedo, G. A. (2016). Enzymatic biotransformation of polyphenolics increases antioxidant activity of redand white grape pomace. Food Research International, 89, 533-539.

Ramírez-Garza, S. L., Laveriano-Santos, E. P., Marhuenda-Muñoz, M., Storniolo, C. E., Tresserra-Rimbau, A., Vallverdú-Queralt, A., Lamuela-Raventós, R. M. (2018). Health effects of resveratrol: Results from human intervention trials. Nutrients, 10(12), 1892.

Singleton, V. L., Rossi, J. J. A. (1965). Colorimetric of totalmphenolics with phosphomolybdicphosphotungstic acid reagents. American Journal of Enology and Viticulture,16(3), 144-158.

Spigno, G., De Faveri, D. M. (2007). Antioxidants from grape stalks and marc: Influence of extraction procedure on yield, purity and antioxidant power of the extracts. Journal of Food Engineering, 78, 793-801.

Stagos, D., Kazantzoglou, G., Theofanidou, D., Kakalopoulou, G., Magiatis, P., Mitaku, S., Kouretas, D., 2006. Activity of grape extracts from Greek varieties of Vitis vinifera against mutagenicity induced by bleomycin and hydrogenperoxide in Salmonella typhimurium strain TA102. Mutation Research, 609(2), 165-175.

Surguladze, M. A., Bezhuashvili, M. G. (2017). Impact of wine technology on the variability of resveratrol and piceids in Saperavi (Vitis vinifera L.). Annals of Agrarian Science, 14(3), 1-4.

Vázquez-Armenta, F. J., Silva-Espinoza, B.A., Cruz-Valenzuela, M.R., González Aguilar, G.A., Nazzaro, F., Fratianni, F. (2017). Antibacterial and antioxidant properties of grape stem extract applied as disinfectant in fresh leafy vegetables. Journal of Food Science \& Technology, 54(10), 3192-3200.

Waterhouse, A. L. (2005). Determination of total phenolics, in Handbook of Food Analytical Chemistry, ed. by Wrolstad, R. E., Acree, T. E., Decker, E. A., Penner, M. H., Reid, D. S., Schwartz, S. J., Shoemaker, C. F., Smith, D. M., Sporns, P. John Wiley \& Sons, 463-470, New Jersey.

Yoshino, J., Conte, C., Fontana, L., Mittendorfer, B., Imai, S.I., Schechtman, K. B., Gu, C., Kunz, I., Fanelli, F.R., Patterson, B.W. (2012) Resveratrol supplementation does not improve metabolic function in nonobese women with normal glucose tolerance. Cell Metabolism, 16, 658-66. 